\title{
Influence of Minimal Changes in Preoperative Renal Function on Outcomes of Cardiac Surgery
}

\author{
Linda Shavit $^{\mathrm{a}} \quad$ Rachel Tauber $^{\mathrm{b}}$ Meyer Lifschitz ${ }^{\mathrm{a}}$ Daniel Bitran ${ }^{\mathrm{b}} \quad$ Itzchak Slotki $^{\mathrm{a}}$ \\ Daniel Fink ${ }^{b}$
}

${ }^{a}$ Adult Nephrology Unit and b Department of Cardiac Surgery, Shaare Zedek Medical Center, Jerusalem, Israel

\section{Key Words}

Preoperative creatinine $\cdot$ Cardiothoracic surgery •

Estimated glomerular filtration rate $\cdot$ Mortality

Postoperative dialysis

\begin{abstract}
Background/Aims: Cardiovascular morbidity and mortality are high in patients with chronic kidney disease. We evaluated the influence of small differences in preoperative kidney function on mortality and complications following cardiac surgery. Methods: This is an observational study that included adult patients undergoing cardiac surgery. Preoperative estimated glomerular filtration rate (eGFR) was estimated by the 4-component Modification of Diet in Renal Disease (MDRD) and Chronic Kidney Disease Epidemiology Collaboration (CKD-EPI) equations based on preoperative creatinine levels. For analysis, patients were divided into groups according to their preoperative creatinine $(0.2 \mathrm{mg} / \mathrm{dl}$ increments) and eGFR levels (15-30 ml/min $/ 1.73 \mathrm{~m}^{2}$ decrements). Results: Data on 5,340 patients were analyzed. A significant increase in postoperative mortality was demonstrated with preoperative creatinine at high-normal versus low-normal values (OR 1.7, 95\% Cl: 1-2.5; $p=0.02$ ). For preoperative creatinine $>1.2$ $\mathrm{mg} / \mathrm{dl}$, adjusted OR for in-hospital mortality increased stepwise with every $0.2-\mathrm{mg} / \mathrm{dl}$ increment of creatinine. In addition, a statistically significant increment of mortality was de-
\end{abstract}

tected with every $15-\mathrm{ml} / \mathrm{min} / 1.73 \mathrm{~m}^{2}$ decrement in preoperative eGFR. Conclusions: Minimal changes of preoperative kidney function are associated with a substantial increase in the risk of mortality and morbidity following cardiac surgery. Even within the 'normal' range, minimal increases in serum creatinine levels are associated with increased risk of adverse events postoperatively.

Copyright $\odot 2012$ S. Karger AG, Basel

\section{Introduction}

Cardiovascular morbidity is high in patients with chronic kidney disease (CKD). Patients with CKD have an increased prevalence of coronary artery disease, silent myocardial ischemia, cardiac arrhythmias, and valvular calcifications when compared with patients with normal renal function [1-4]. Kidney injury, both acute and chronic, is considered as a significant risk factor for increased morbidity and mortality in patients undergoing open heart surgery [2-4]. It is well known that development of acute kidney injury (AKI) following cardiac surgery is associated with a high mortality and more complicated hospital course [5]. Even small changes in serum creatinine in the postoperative period are clinically significant and predict decreased survival [1]. However, the effect of minimally raised preoperative serum creatinine

\section{KARGER \\ Fax +4161306 1234 \\ E-Mail karger@karger.ch}

www.karger.com
(C) 2012 S. Karger AG, Basel

$1420-4096 / 12 / 0356-0400 \$ 38.00 / 0$

Accessible online at:

www.karger.com/kbr
Linda Shavit, MD

Adult Nephrology Unit, Shaare Zedek Medical Center

PO Box 3235

Jerusalem 91031 (Israel)

Tel. +972 2655 5086, E-Mail lshavit@ szmc.org.il 
or reduced estimated glomerular filtration rate (eGFR) on the rate of operative and postoperative complications and mortality has not been previously explored.

An accurate assessment of the influence of different degrees of renal dysfunction on operative outcome becomes especially important due to the increased number of CKD patients with cardiovascular disease requiring cardiac surgery. eGFR calculated by the Modification of Diet in Renal Disease (MDRD) study formula, has been widely used to determine the association of GFR with postoperative complications, but has limited precision and systematically underestimates eGFR at higher values [4]. Recently, a new estimating formula, the Chronic Kidney Disease Epidemiology Collaboration (CKD-EPI) equation, was introduced and proposed to be as accurate as the MDRD study equation at a GFR $<60 \mathrm{ml} / \mathrm{min} /$ $1.73 \mathrm{~m}^{2}$ (CKD III) and more accurate at a higher GFR [6]. The aim of our study was to determine the influence of subtle differences in preoperative renal function, as determined by serum creatinine levels and eGFR using MDRD and CKD-EPI equations, on the rate of operative and postoperative complications and mortality.

\section{Materials and Methods}

\section{Study Population and Data Collection}

This is an observational study in which all data were collected prospectively on a daily basis by research assistants who completed a preoperative, intraoperative and postoperative datasheet. The preoperative and intraoperative datasheet contains variables related to the severity of disease and comorbid factors before surgery and operative features. The postoperative datasheet contains variables related to in-hospital outcomes after surgery.

Eligible patients included individuals 18 years of age or older undergoing cardiac surgery from February 1997 to January 2010, in our hospital either electively or urgently. Patients on preoperative chronic dialysis were excluded. Written consent was not obtained from the individual patients, as the study is based on data collected for routine care. Local ethics committee approval is not required in Israel for observational studies.

\section{Study Methods}

Preoperative eGFR was estimated in all patients by the 4-component MDRD and CKD-EPI equations based on preoperative creatinine levels (reference range: $0.66-1.2 \mathrm{mg} / \mathrm{dl}$, isotope dilution mass spectrometry corrected). Initially, we divided the patients into two groups according to their preoperative eGFR levels: eGFR $>60 \mathrm{ml} / \mathrm{min} / 1.73 \mathrm{~m}^{2}$ and $\mathrm{eGFR}<60 \mathrm{ml} / \mathrm{min} / 1.73 \mathrm{~m}^{2}$.

The following preoperative patient-related characteristics were recorded: age, gender, medical history of heart failure (according NYHA classification), left main coronary artery disease, diabetes, hypertension, hyperlipidemia, peripheral vascular disease, cerebral vascular accident (CVA) and chronic obstructive pulmonary disease. Operative features included: type of operation performed (coronary artery bypass grafting, valvular, or combined), incidence and indications for intra-aortic balloon pump use, surgery status (elective, emergent, emergent/salvage and urgent), perfusion time, cross clamp time and use of off-pump surgery. Postoperative complications recorded included AKI requiring dialysis, infections, prolonged mechanical ventilation ( $>24 \mathrm{~h})$, CVA, myocardial infarction, acute respiratory distress syndrome, in-hospital mortality incidence and causes, ICU and in-hospital stay.

As a second step we divided patients into smaller groups according to preoperative creatinine $(0.2-\mathrm{mg} / \mathrm{dl}$ increments) and eGFR (based on the National Kidney Foundation CKD classification: stage I eGFR $>90 \mathrm{ml} / \mathrm{min} / 1.73 \mathrm{~m}^{2}$, stage II eGFR $61-90 \mathrm{ml} /$ $\mathrm{min} / 1.73 \mathrm{~m}^{2}$, early and late stage III eGFR $46-60$ and $30-45 \mathrm{ml} /$ $\mathrm{min} / 1.73 \mathrm{~m}^{2}$, respectively, stage IV eGFR $15-29 \mathrm{ml} / \mathrm{min} / 1.73 \mathrm{~m}^{2}$ ) to determine the influence of minimal differences in these parameters on postoperative outcomes, after adjustment for all previously determined clinical risk factors.

\section{Outcomes}

The studied outcomes were postoperative AKI requiring dialysis, in-hospital mortality (regardless of length of stay), and major morbidities including neurologic (CVA) and infectious (septic shock or other infections requiring intravenous antibiotics).

\section{Statistical Analysis}

Analysis was performed using SPSS software version 11.0 (SPSS Inc.). The association of potential risk factors with postoperative mortality or morbidity was assessed by univariate analysis: nominal and categorical variables were compared using the $\chi^{2}$ likelihood ratio or Fisher's exact test. Continuous variables were compared using the nonparametric Wilcoxon test. Factors with $\mathrm{p} \leq 0.05$ were included in a stepwise regression model. In the multivariable analysis, we included the eight groups of patents classified by preoperative serum creatinine and eGFR levels. For all groups of patients, $\mathrm{p}$ values were obtained through comparisons of the selected group with the reference group with normal preoperative eGFR and creatinine levels. Adjustment was performed for confounders that were identified as significant by the univariate analysis. Preoperative creatinine and eGFR were included in two separate models using multivariate logistic regression analysis. In addition, a cubic spline to GFR and risk of death was performed in order to describe the predictive value of different values of preoperative GFR and explore appropriate clinical thresholds. An analysis of correlation between small preoperative increments in serum creatinine or decrements in eGFR on postoperative AKI defined by the RIFLE criteria ['R' (risk), 'I' (injury), 'F' (failure) stages] was performed using a $\chi^{2}$ likelihood ratio and Fisher's exact test. Data were expressed as means (SD), with differences reported as significant if $\mathrm{p}<0.05$.

\section{Results}

A total of 5,340 patients underwent cardiac surgery from February 1997 to January 2010, and were included in the analyses. Of these, 3,655 (69\%) had preoperative eGFR $>60 \mathrm{ml} / \mathrm{min} / 1.73 \mathrm{~m}^{2}$ and 1,654 (31\%) had eGFR $<60 \mathrm{ml} / \mathrm{min} / 1.73 \mathrm{~m}^{2}$ (by MDRD equation). 
Table 1. Baseline patient and procedure-related characteristics

\begin{tabular}{|c|c|c|c|}
\hline & $\begin{array}{l}\text { eGFR }>60 \\
\mathrm{ml} / \mathrm{min} / 1.73 \mathrm{~m}^{2} \\
(\mathrm{n}=3,655 ; 69 \%)\end{array}$ & $\begin{array}{l}\text { eGFR } 15-60 \\
\mathrm{ml} / \mathrm{min} / 1.73 \mathrm{~m}^{2} \\
(\mathrm{n}=1,655 ; 31 \%)\end{array}$ & $\mathrm{p}$ value \\
\hline \multicolumn{4}{|l|}{ Patient characteristics } \\
\hline Gender, males & $2,743(75)$ & $980(59)$ & $<0.0001$ \\
\hline Age, years & $61 \pm 12$ & $70 \pm 9$ & $<0.0001$ \\
\hline Preop. $\mathrm{S}_{\text {cre }} \mathrm{mg} / \mathrm{dl}$ & $0.9 \pm 0.2$ & $1.5 \pm 0.5$ & $<0.0001$ \\
\hline \multicolumn{4}{|c|}{ CHF NYHA classification } \\
\hline I & $1,746(48)$ & $532(32)$ & $<0.0001$ \\
\hline II & $570(16)$ & $207(12)$ & 0.003 \\
\hline III & $715(20)$ & $416(25)$ & $<0.0001$ \\
\hline IV & $359(10)$ & $402(24)$ & $<0.0001$ \\
\hline Left main artery $>50 \%$ & $568(16)$ & $262(12)$ & NS 0.8 \\
\hline PVD & $401(11)$ & $287(17)$ & $<0.0001$ \\
\hline Hyperlipidemia & $2,027(55)$ & $938(57)$ & NS 0.4 \\
\hline HTN & $1,930(53)$ & $1,175(71)$ & $<0.0001$ \\
\hline $\mathrm{DM}$ & $1,233(34)$ & $621(38)$ & 0.007 \\
\hline CVA & $281(8)$ & $208(13)$ & $<0.0001$ \\
\hline COPD & $255(7)$ & $158(10)$ & 0.001 \\
\hline \multicolumn{4}{|l|}{ Procedure characteristics } \\
\hline \multicolumn{4}{|l|}{ Type of procedure } \\
\hline CABG & $2,453(67)$ & $912(55)$ & $<0.0001$ \\
\hline CABG +1 valve & $332(9)$ & $230(14)$ & $<0.0001$ \\
\hline $\mathrm{CABG}+2$ valves & $30(1)$ & $32(2)$ & 0.0005 \\
\hline MVR alone & $218(6)$ & $123(7)$ & 0.04 \\
\hline AVR alone & $227(6)$ & $103(6)$ & NS 0.9 \\
\hline $\mathrm{MVR}+\mathrm{AVR}$ & $75(2)$ & $48(3)$ & NS 0.06 \\
\hline Other & $122(3)$ & $40(2)$ & NS 0.07 \\
\hline \multicolumn{4}{|l|}{ Surgery status } \\
\hline Elective & $2,780(76)$ & $1,211(73)$ & 0.03 \\
\hline Emergent & $126(3)$ & $88(5)$ & 0.001 \\
\hline Emergent/salvage & $23(1)$ & $28(2)$ & 0.002 \\
\hline IABP & $152(4)$ & $142(9)$ & $<0.0001$ \\
\hline Cross clamp time, $\min$ & $65 \pm 33$ & $73 \pm 45$ & $<0.0001$ \\
\hline Perfusion time, $\min$ & $100 \pm 47$ & $113 \pm 55$ & $<0.0001$ \\
\hline
\end{tabular}

Data are expressed as numbers (\%) unless indicated otherwise. $\mathrm{DM}=$ Diabetes mellitus; $\mathrm{HTN}=$ hypertension $; \mathrm{CHF}=$ congestive heart failure; COPD = chronic obstructive pulmonary disease; IABP = intra-aortic balloon pump; PVD = peripheral vascular disease; $\mathrm{CABG}=$ coronary artery bypass graft; $\mathrm{AVR}=$ aortic valve replacement; $\mathrm{MVR}$ = mitral valve replacement.

\section{eGFR by MDRD or CKD-EPI Equation}

By the CKD-EPI equation, 3\% of the study patients had CKD stage IV (eGFR 15-30 ml/min/1.73 $\mathrm{m}^{2}$ ), 28\% had CKD stage III (eGFR $30-60 \mathrm{ml} / \mathrm{min} / 1.73 \mathrm{~m}^{2}$ ) and $69 \%$ of patients had eGFR $>60 \mathrm{ml} / \mathrm{min} / 1.73 \mathrm{~m}^{2}$.

Corresponding values using the MDRD equation were $4 \%$ for stage IV, $29 \%$ for stage III and $67 \%$ for eGFR $>60$ $\mathrm{ml} / \mathrm{min} / 1.73 \mathrm{~m}^{2}$ (differences nonsignificant).
Table 2. Postoperative complications and mortality

\begin{tabular}{|c|c|c|c|}
\hline $\begin{array}{l}\text { Complications } \\
\text { and mortality }\end{array}$ & $\begin{array}{l}\text { eGFR }>60 \\
\mathrm{ml} / \mathrm{min} / 1.73 \mathrm{~m}^{2} \\
(\mathrm{n}=3,655 ; 69 \%)\end{array}$ & $\begin{array}{l}\text { eGFR } 15-60 \\
\mathrm{ml} / \mathrm{min} / 1.73 \mathrm{~m}^{2} \\
(\mathrm{n}=1,655 ; 31 \%)\end{array}$ & $\mathrm{p}$ value \\
\hline ARF dialysis & $9(0.25)$ & $27(2)$ & $<0.0001$ \\
\hline Infections-total & $436(12)$ & $314(19)$ & $<0.0001$ \\
\hline Sepsis & $70(2)$ & $113(7)$ & $<0.0001$ \\
\hline Pneumonia & $43(1)$ & $47(3)$ & $<0.0001$ \\
\hline \multicolumn{4}{|l|}{ Prolonged } \\
\hline ventilation $>24 \mathrm{~h}$ & $238(6)$ & 319 (19) & $<0.0001$ \\
\hline Perioperative MI & $67(2)$ & $48(3)$ & 0.01 \\
\hline ARDS & $24(0.6)$ & $24(1)$ & 0.007 \\
\hline CVA & $35(1)$ & $49(3)$ & $<0.0001$ \\
\hline Mortality & $97(3)$ & $183(11)$ & $<0.0001$ \\
\hline \multicolumn{4}{|l|}{ Cause of death } \\
\hline Cardiac & $59(61)$ & $61(33)$ & $<0.0001$ \\
\hline Infection & $11(11)$ & $61(33)$ & $<0.0001$ \\
\hline Neurological & $10(10)$ & $18(10)$ & 0.9 \\
\hline Days in ICU & $3 \pm 7$ & $6 \pm 13$ & $<0.0001$ \\
\hline Days in hospital & $12 \pm 12$ & $18 \pm 20$ & $<0.0001$ \\
\hline
\end{tabular}

Data are expressed as numbers (\%) unless indicated otherwise. $\mathrm{ARF}=$ Acute renal failure; $\mathrm{MI}=$ myocardial infarction; $\mathrm{ARDS}=$ acute respiratory distress syndrome.

Table 1 represents the baseline patient and procedure-related characteristics of the study population with eGFR $>$ or $<60 \mathrm{ml} / \mathrm{min} / 1.73 \mathrm{~m}^{2}$. Significant differences between groups were evident at baseline. Patients with eGFR $<60 \mathrm{ml} / \mathrm{min} / 1.73 \mathrm{~m}^{2}$ were older; had a higher incidence of comorbidities including advanced congestive heart failure (NYHA classes III and IV), diabetes, hypertension, CVA and peripheral vascular disease; and required more prolonged, urgent and complicated operative intervention compared to patients with eGFR $>60$ $\mathrm{ml} / \mathrm{min} / 1.73 \mathrm{~m}^{2}$.

Postoperative complications and mortality according to eGFR ( $>$ or $<60 \mathrm{ml} / \mathrm{min} / 1.73 \mathrm{~m}^{2}$ ) are presented in table 2. The following complications were significantly more common in the group with eGFR $<60 \mathrm{ml} / \mathrm{min} /$ $1.73 \mathrm{~m}^{2}$ : AKI requiring hemodialysis $(0.25$ vs. $2 \%, \mathrm{p}<$ 0.0001 ), sepsis ( 2 vs. $7 \%, \mathrm{p}<0.0001$ ), prolonged mechanical ventilation ( 6 vs. $19 \%, \mathrm{p}<0.0001$ ), longer hospital stay $(12 \pm 12$ vs. $18 \pm 20$ days, $\mathrm{p}<0.0001)$ and mortality (3 vs. $11 \%, \mathrm{p}<0.0001)$. However, after adjustment for confounders detected by univariate analysis (including comorbidities and surgery-related characteristics, total of 10 confounders), age $>65$ years, preoperative creatinine $>1.2 \mathrm{mg} / \mathrm{dl}$, eGFR $<60 \mathrm{ml} / \mathrm{min} / 1.73 \mathrm{~m}^{2}$, congestive heart failure NYHA IV, and emergent surgery remained inde- 


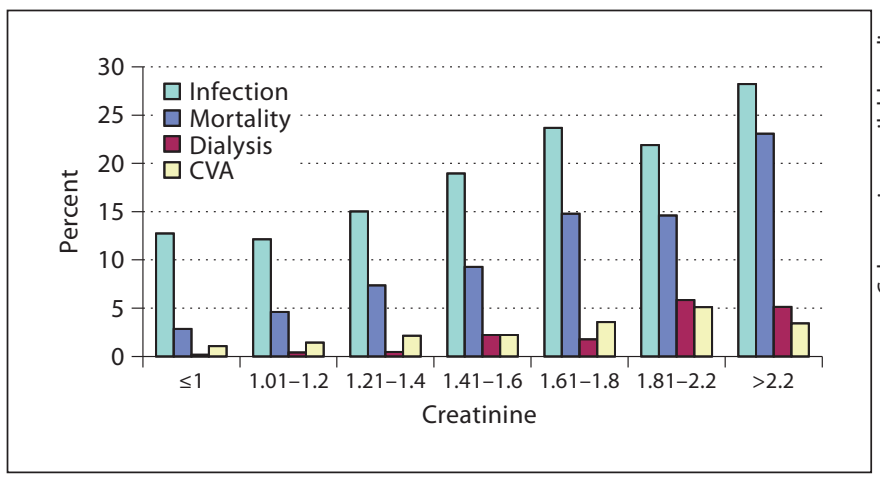

Fig. 1. Frequency of postoperative infection, mortality, AKI requiring dialysis and CVA according to preoperative serum creatinine.

pendent risk factors for mortality. Preoperative creatinine $>1.2 \mathrm{mg} / \mathrm{dl}$ was an independent risk factor for inhospital mortality (OR 2.2, 95\% CI: 1.4-3.4), dialysis (OR 4, 95\% CI: 2-9.8), CVA (OR 1.6, 95\% CI: 0.9-3) and postoperative infection (OR 1.2, 95\% CI: 1-1.5). Preoperative eGFR $<60 \mathrm{ml} / \mathrm{min} / 1.73 \mathrm{~m}^{2}$ (compared with preoperative eGFR >60) was an independent risk factor for postoperative CVA (OR 2.3, 95\% CI: 1.4-3.7), in-hospital mortality (OR 2.4, 95\% CI: 1.8-3.3), and dialysis (OR 3.1, 95\% CI: 1.6-8), but not for infectious complications (online suppl. table 1; for all online supplementary material, see www. karger.com/doi/10.1159/000335950).

Figures 1 and 2 (see also online suppl. fig. 1 and 2 for the corresponding tables) demonstrate the effect of preoperative serum creatinine and eGFR levels on the incidence of four major postoperative outcomes: AKI requiring dialysis, infection, CVA and mortality. A gradual and stepwise increment in the incidence of all four outcomes was detected for every $0.2-\mathrm{mg} / \mathrm{dl}$ increment of preoperative creatinine values even within the reference range.

Mortality increased from 2.8 to 4.6 to 7.4 to 9.3 to 14.8 to $23 \%$ in patients with preoperative creatinine values of $<1,1.01-1.2,1.21-1.4,1.41-1.6,1.61-2.2$ and $>2.2 \mathrm{mg} / \mathrm{dl}$, respectively. Similar trends were detected for other outcomes (fig. 1).

Figure 2 demonstrates the incidence of adverse postoperative outcomes in groups of patients stratified by preoperative eGFR. Postoperative mortality and morbidity rose incrementally with each stage of CKD (every 15-30 $\mathrm{ml} / \mathrm{min} / 1.73 \mathrm{~m}^{2}$ decrease in preoperative eGFR).

Adjusted ORs for postoperative mortality in patients with different serum creatinine and eGFR levels are dem-

Preoperative Renal Function and

Outcomes of Cardiothoracic Surgery

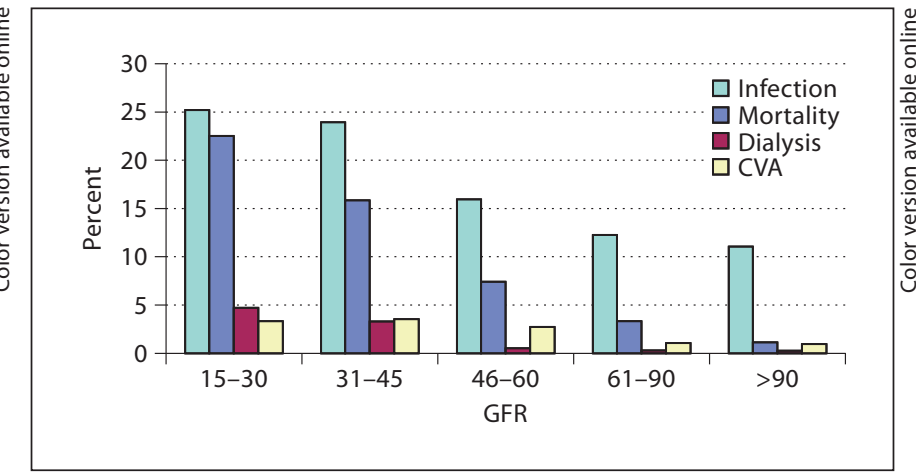

Fig. 2. Frequency of postoperative infection, mortality, AKI requiring dialysis and CVA according to preoperative eGFR.

onstrated in figures 3 and 4 (see also online suppl. fig. 3 and 4 for the corresponding tables). A significant increase in postoperative mortality was demonstrated with preoperative creatinine at high-normal versus low-normal values (OR 1.7, 95\% CI: 1-2.5; $\mathrm{p}=0.02)$. With preoperative creatinine $>1.2 \mathrm{mg} / \mathrm{dl}$, the adjusted OR for in-hospital mortality increased stepwise from 2 for patients with creatinine $1.21-1.4 \mathrm{mg} / \mathrm{dl}$ to 3.2 in patients with creatinine $1.41-1.6 \mathrm{mg} / \mathrm{dl}$ to 3.6 in patients with creatinine $1.61-2.2$ $\mathrm{mg} / \mathrm{dl}$ to 6.6 in patients with creatinine $>2.2 \mathrm{mg} / \mathrm{dl}$ (fig. 3). No significant effect of serum creatinine on postoperative dialysis or CVA was observed (data not shown).

When eGFR (estimated by the MDRD equation) was used as the indicator of kidney function, a statistically significant increment in mortality was detected with every $15-\mathrm{ml} / \mathrm{min} / 1.73 \mathrm{~m}^{2}$ decrement of preoperative eGFR (fig. 4). The adjusted OR for in-hospital mortality increased sharply from 2 for patients with eGFR 61-90 to 3 in patients with eGFR 46-60 to 9.1 in patients with eGFR $31-45$ to 20 in patients with eGFR $15-30 \mathrm{ml} /$ $\min / 1.73 \mathrm{~m}^{2}$.

Online supplementary figure 5 demonstrates a cubic spline analysis for hazard of death with decreasing preoperative eGFR. The risk of death increased sharply with eGFR $<60 \mathrm{ml} / \mathrm{min} / 1.73 \mathrm{~m}^{2}$ and continued to increase steeply with each subsequent decrement in eGFR.

No relationship was demonstrated between small differences in preoperative eGFR $\left(15-\mathrm{ml} / \mathrm{min} / 1.73 \mathrm{~m}^{2}\right.$ decrements) and postoperative need for dialysis or occurrence of CVA (not shown). Use of the CKD-EPI equation yielded similar results (data not shown).

The effect of small preoperative increments in serum creatinine or decrements in eGFR on postoperative AKI 


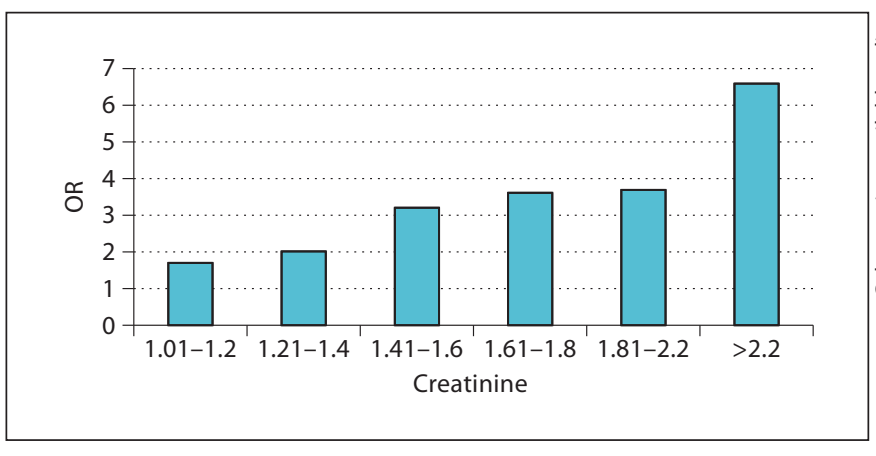

Fig. 3. Adjusted ORs for postoperative mortality according to serum creatinine. Values obtained by multivariate analysis after adjustment for previously identified confounders. Selected groups were compared to the reference group with preoperative plasma creatinine $<1 \mathrm{mg} / \mathrm{dl}$.

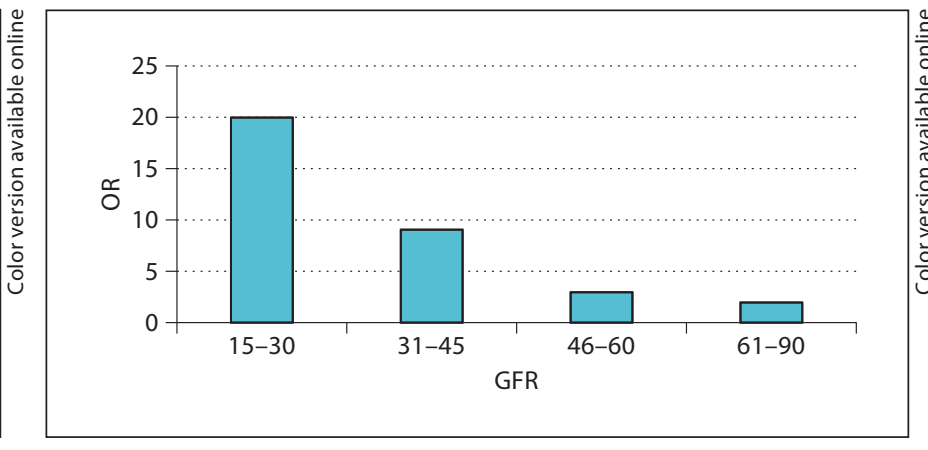

Fig. 4. Adjusted ORs for postoperative mortality according to eGFR. Values obtained by multivariate analysis after adjustment for previously identified confounders. Selected groups were compared to the reference group with preoperative eGFR $>90 \mathrm{ml} /$ $\min / 1.73 \mathrm{~m}^{2}$

Table 3. Effect of small preoperative increments in serum creatinine or decrements in eGFR on postoperative AKI as defined by the RIFLE criteria

\begin{tabular}{|c|c|c|c|c|c|c|c|c|c|c|}
\hline & \multicolumn{7}{|c|}{ Preoperative creatinine, $\mathrm{mg} / \mathrm{dl}$} & \multicolumn{3}{|c|}{ Preoperative eGFR, $\mathrm{ml} / \mathrm{min} / 1.73 \mathrm{~m}^{2}$} \\
\hline & $\begin{array}{l}>2.2 \\
(n=56)\end{array}$ & $\begin{array}{l}1.8-2.2 \\
(n=64)\end{array}$ & $\begin{array}{l}1.6-1.8 \\
(n=75)\end{array}$ & $\begin{array}{l}1.4-1.6 \\
(n=131)\end{array}$ & $\begin{array}{l}1.2-1.4 \\
(\mathrm{n}=203)\end{array}$ & $\begin{array}{l}1-1.2 \\
(n=84)\end{array}$ & $\begin{array}{l}\leq 1 \\
(n=58)\end{array}$ & $\begin{array}{l}46-60 \\
(n=395)\end{array}$ & $\begin{array}{l}31-45 \\
(n=208)\end{array}$ & $\begin{array}{l}15-30 \\
(n=68)\end{array}$ \\
\hline Risk & $7(12)$ & $9(14)$ & $7(9)$ & $8(6)$ & $16(8)$ & $10(12)$ & $6(10)$ & $32(8)$ & $21(10)$ & $10(15)$ \\
\hline Injury & $8(14)$ & $6(9)$ & $5(7)$ & $8(6)$ & $10(5)$ & $8(10)$ & $2(4)$ & $24(6)$ & $15(7)$ & $8(12)$ \\
\hline Failure & $16(29)^{* *}$ & $7(11)$ & $5(7)$ & $9(7)$ & $6(3)$ & $2(2)$ & $0^{*}$ & $12(3)^{* *}$ & $17(8)$ & $16(24)^{* *}$ \\
\hline
\end{tabular}

Values in parentheses are percentages unless indicated otherwise. ${ }^{*} \mathrm{p}=0.02 ;{ }^{* *} \mathrm{p}<0.0001$.

defined by the RIFLE criteria was examined in 679 patients with available data. Of those who developed AKI, 63 were classified as 'risk', 43 as 'injury' and 45 as 'failure'. The incidence of 'failure' was $24 \%$ in patients with eGFR $15-30$ and $3 \%$ in patients with eGFR $45-60 \mathrm{ml} / \mathrm{min} /$ $1.73 \mathrm{~m}^{2}(\mathrm{p}<0.001)$. However, although the incidence of 'risk' and 'injury' also rose inversely with eGFR, this finding did not reach statistical significance. Moreover, more subtle decrements in preoperative eGFR did not have a statistically significant influence on postoperative AKI as defined by the RIFLE criteria. Similarly for preoperative creatinine levels, a statistically significant increase in incidence of failure, but not risk or injury, was seen only in patients with significant kidney dysfunction (no patients with failure were detected in patients with preoperative creatinine $<1 \mathrm{mg} / \mathrm{dl}$ compared to $29 \%$ in patients with $>2.2 \mathrm{mg} / \mathrm{dl}, \mathrm{p}<0.001$; table 3 ).

\section{Discussion}

In this large prospective cohort study, we demonstrated a substantial increase in the risk of death and other adverse postoperative outcomes with every $0.2-\mathrm{mg} / \mathrm{dl}$ increment of preoperative creatinine values even within the normal range. In addition, a dramatic increase in postoperative mortality was shown with small decrements of preoperative eGFR. The adjusted OR for in hospital mortality increased sharply from 2 for patients with eGFR $61-90 \mathrm{ml} / \mathrm{min} / 1.73 \mathrm{~m}^{2}$ to 20 in patients with eGFR $15-30$ $\mathrm{ml} / \mathrm{min} / 1.73 \mathrm{~m}^{2}$ compared to patients with eGFR $>90 \mathrm{ml} /$ $\min / 1.73 \mathrm{~m}^{2}$.

The strong association between renal function and outcome after cardiac surgery has been demonstrated in previous studies. Durmaz et al. [2] were the first to report increased in-hospital mortality rates of 11.8, 33.0 and $12.5 \%$ in patients who had creatinine levels between 1.6 
and $2.5 \mathrm{mg} / \mathrm{dl},>2.5 \mathrm{mg} / \mathrm{dl}$ and end-stage renal disease on hemodialysis, respectively. In 2002 Weerasinghe et al. [3] demonstrated that a mild elevation $(1.31-1.5 \mathrm{mg} / \mathrm{dl})$ in preoperative serum creatinine level significantly increased the need for renal replacement therapy, the duration of special care, total postoperative stay and in-hospital mortality. Penta de Peppo et al. [7] analyzed data from 159 consecutive patients with moderate-to-end-stage renal dysfunction, who underwent surgery using cardiopulmonary bypass and detected satisfactory early and late surgical outcomes in patients with moderate renal failure (preoperative serum creatinine levels of 1.9-2.5 $\mathrm{mg} / \mathrm{dl}$ ), but poor outcomes in patients with severe nondialysis-dependent renal dysfunction (serum creatinine $>2.5 \mathrm{mg} / \mathrm{dl}$ ) and in chronic hemodialysis patients.

Several recent studies yielded similar results and concluded that CKD is common in the cardiac surgery population and preoperative 'mild-to-moderate' renal dysfunction is an important predictor of outcome in terms of in-hospital mortality, morbidity and midterm survival $[4,8-10]$. However, most of these studies assessed the association between renal function and outcome after cardiac surgery by dichotomizing renal function, using a serum creatinine level between 1.4 and $2.2 \mathrm{mg} / \mathrm{dl}$ as a cutoff point to diagnose 'mild renal dysfunction'. The single study in which eGFR was examined as a continuous variable clearly demonstrated an increased mortality risk with decreasing preoperative eGFR as a continuous variable [9]. We were unable to show a graded increase in the risk of death and other adverse postoperative outcomes with minimal increases in preoperative creatinine even within the reference range.

In addition, we confirmed a stepwise increase in mortality, postoperative CVA, dialysis and infection inversely related to preoperative eGFR. For example, the incidence of postoperative CVA rose from 0.8 to $3.3 \%$ in patients with preoperative eGFR $>80$ to $<45 \mathrm{ml} / \mathrm{min} /$ $1.73 \mathrm{~m}^{2}$. Multivariable analysis showed that eGFR $<60$ $\mathrm{ml} / \mathrm{min} / 1.73 \mathrm{~m}^{2}$ was an independent risk factor for CVA with an adjusted OR of 2.3 (95\% CI: 1.4-3.7). A dramatic increase in the adjusted OR for postoperative mortality was demonstrated with subtle decrements in preoperative eGFR.

In addition, in our study population, the CKD-EPI formula, which has been proposed as improving CKD staging [6], performed similar to the MDRD formula.

Substantial clinical evidence demonstrates that eGFR is superior to creatinine for both more accurate evaluation of renal function and as a strong and independent predictor of postoperative outcome [11-14]. Moreover,

Preoperative Renal Function and

Outcomes of Cardiothoracic Surgery
eGFR is superior to serum creatinine in predicting late ( $>15$ years of follow up) all-cause and cardiovascular mortality and morbidity at a cutoff value of $<60 \mathrm{ml} / \mathrm{min} /$ $1.73 \mathrm{~m}^{2}$ [12]. Thus, preoperative GFR estimation provides a better risk assessment in patients scheduled for heart surgery and eGFR may improve the predictive accuracy for morbidity and mortality in a variety of clinical settings, including patients undergoing cardiac surgery.

Our study was mainly focused on the predictive value of preoperative CKD. An additional factor to be considered is the impact of postoperative AKI on outcomes. In this regard, Kuitunen et al. [15] have shown that postoperative AKI, defined by the standardized RIFLE classification, was highly predictive of the 90 -day mortality rate. However, in contrast to the unfavorable effect of preoperative CKD on postoperative mortality, we were unable to demonstrate a significant correlation between small preoperative increments in serum creatinine or decrements in eGFR on postoperative AKI as defined by RIFLE criteria.

In our study, the influence of the various preoperative strata of kidney function on the milder 'R' and 'I' stages of postoperative AKI was available only in a subset of our patients. Clearly, it would be of great interest to explore both the effect of preoperative renal dysfunction on postoperative RIFLE stages of AKI as well as the combined effects of preoperative renal dysfunction and postoperative RIFLE stages of AKI on mortality and other postoperative outcomes in larger patient populations. This information could then be used to define specific cutoff values for each parameter, thereby enabling the establishment of an accurate risk model for postoperative AKI, mortality and other morbidities and paving the way for testing potential interventions.

Our study has some limitations. First, it was based on observational data and we cannot entirely rule out known or unknown confounding factors as an explanation for our results. Differences in outcomes in our study could also be due to unintended differences in treatment factors, or even in outcome measures. However, recall bias can be excluded in our study since there was no difference in the reliability of the data collected and the same research assistants completed a preoperative, intraoperative and postoperative datasheet prospectively on a daily basis. In addition, no changes in definitions of comorbidities or studied outcomes were performed during the whole period of the study. A further limitation is that our measure of CKD was only based on estimated and not measured GFR. This may have led to some misclassification of CKD status, particularly in patients with eGFR 
close to or $>60 \mathrm{ml} / \mathrm{min} / 1.73 \mathrm{~m}^{2}$ [16]. Notwithstanding these drawbacks, our data reinforce the exquisite dependence of cardiac surgical outcomes on preoperative kidney function.

In summary, we evaluated a large cohort of patients undergoing cardiac surgery and demonstrated a substantial increase in the risk of death and other adverse postoperative outcomes with minimal changes in preopera- tive serum creatinine and eGFR. The significance of our results is underlined by the fact that the cardiac surgery population is aging and, hence, renal functional decline is becoming more prevalent. Therefore, our findings highlight the important role of risk stratification in terms of renal function as part of the decision-making process prior to cardiopulmonary bypass surgery.

\section{References}

$>1$ Lassnigg A, Schmidlin D, Mouhieddine M, Bachmann LM, Druml W, Bauer P, Hiesmayr M: Minimal changes of serum creatinine predict prognosis in patients after cardiothoracic surgery: a prospective cohort study. J Am Soc Nephrol 2004;15:1597-1605.

$>2$ Durmaz I, Buket S, Atay Y, Yagdi T, Ozbaran M, Boga M, Alat I, Guzelant A, Basarir S: Cardiac surgery with cardiopulmonary bypass in patients with chronic renal failure. J Thorac Cardiovasc Surg 1999;118:306-315.

$>3$ Weerasinghe A, Hornick P, Smith P, Taylor $\mathrm{K}$, Ratnatunga C: Coronary artery bypass grafting in non-dialysis-dependent mild-tomoderate renal dysfunction. J Thorac Cardiovasc Surg 2001;121:1083-1089.

$\checkmark 4$ Cooper WA, O’Brien SM, Thourani VH, Guyton RA, Bridges CR, Szczech LA, Petersen R, Peterson ED: Impact of renal dysfunction on outcomes of coronary artery bypass surgery: results from the Society of Thoracic Surgeons National Adult Cardiac Database. Circulation 2006;113:1063-1070.

$\checkmark 5$ Chertow GM, Levy EM, Hammermeister KE, Grover F, Daley J: Independent association between acute renal failure and mortality following cardiac surgery. Am J Med 1998; 104:343-348.
Levey AS, Stevens LA, Schmid CH, Zhang YL, Castro AF III, Feldman HI, Kusek JW, Eggers P, Van LF, Greene T, Coresh J: A new equation to estimate glomerular filtration rate. Ann Intern Med 2009;150:604-612.

$\checkmark 7$ Penta de Peppo A, Nardi P, De PR, Pellegrino A, Forlani S, Scafuri A, Chiariello L: Cardiac surgery in moderate to end-stage renal failure: analysis of risk factors. Ann Thorac Surg 2002;74:378-383.

8 Litmathe J, Kurt M, Feindt P, Gams E, Boeken $\mathrm{U}$ : The impact of pre- and postoperative renal dysfunction on outcome of patients undergoing coronary artery bypass grafting (CABG). Thorac Cardiovasc Surg 2009;57: 460-463.

$>9$ Zakeri R, Freemantle N, Barnett V, Lipkin GW, Bonser RS, Graham TR, Rooney SJ, Wilson IC, Cramb R, Keogh BE, Pagano D: Relation between mild renal dysfunction and outcomes after coronary artery bypass grafting. Circulation 2005;112:I270-I275.

-10 Hedley AJ, Roberts MA, Hayward PA, Shaw M, Matalanis G, Buxton BF, Farouque O, Ierino FL: Impact of chronic kidney disease on patient outcome following cardiac surgery. Heart Lung Circ 2010;19:453-459.

-11 van de Wal RM, van Brussel BL, Voors AA, Smilde TD, Kelder JC, van Swieten HA, van Gilst WH, van Veldhuisen DJ, Plokker HW: Mild preoperative renal dysfunction as a predictor of long-term clinical outcome after coronary bypass surgery. J Thorac Cardiovasc Surg 2005;129:330-335.
12 Kangasniemi OP, Mahar MA, Rasinaho E, Satomaa A, Tiozzo V, Lepojarvi M, Biancari F: Impact of estimated glomerular filtration rate on the 15-year outcome after coronary artery bypass surgery. Eur J Cardiothorac Surg 2008;33:198-202.

13 Wang F, Dupuis JY, Nathan H, Williams K: An analysis of the association between preoperative renal dysfunction and outcome in cardiac surgery: estimated creatinine clearance or plasma creatinine level as measures of renal function. Chest 2003;124:18521862.

14 Foot CL, Chinthamuneedi M, Fraser JF, Smith SE, Fayers T, Tesar P, Mullany DV: The association between preoperative eGFR and outcomes in cardiac surgical patients. Crit Care Resusc 2009;11:184-190.

15 Kuitunen A, Vento A, Suojaranta-Ylinen R, Pettila V: Acute renal failure after cardiac surgery: evaluation of the RIFLE classification. Ann Thorac Surg 2006;81:542-546.

16 Coresh J, Selvin E, Stevens LA, Manzi J, Kusek JW, Eggers P, Van LF, Levey AS: Prevalence of chronic kidney disease in the United States. JAMA 2007;298:2038-2047. 